\title{
Teaching Video NeuroImages: Paroxysmal Dysarthria-Ataxia in Multiple Sclerosis
}

Shailee Shah, MD, Bryan T. Klassen, MD, and Eoin P. Flanagan, MD

Neurology ${ }^{\circledR}$ 2021;96:e2245-e2246. doi:10.1212/WNL.0000000000011498

Figure MRI of Brain and Spine
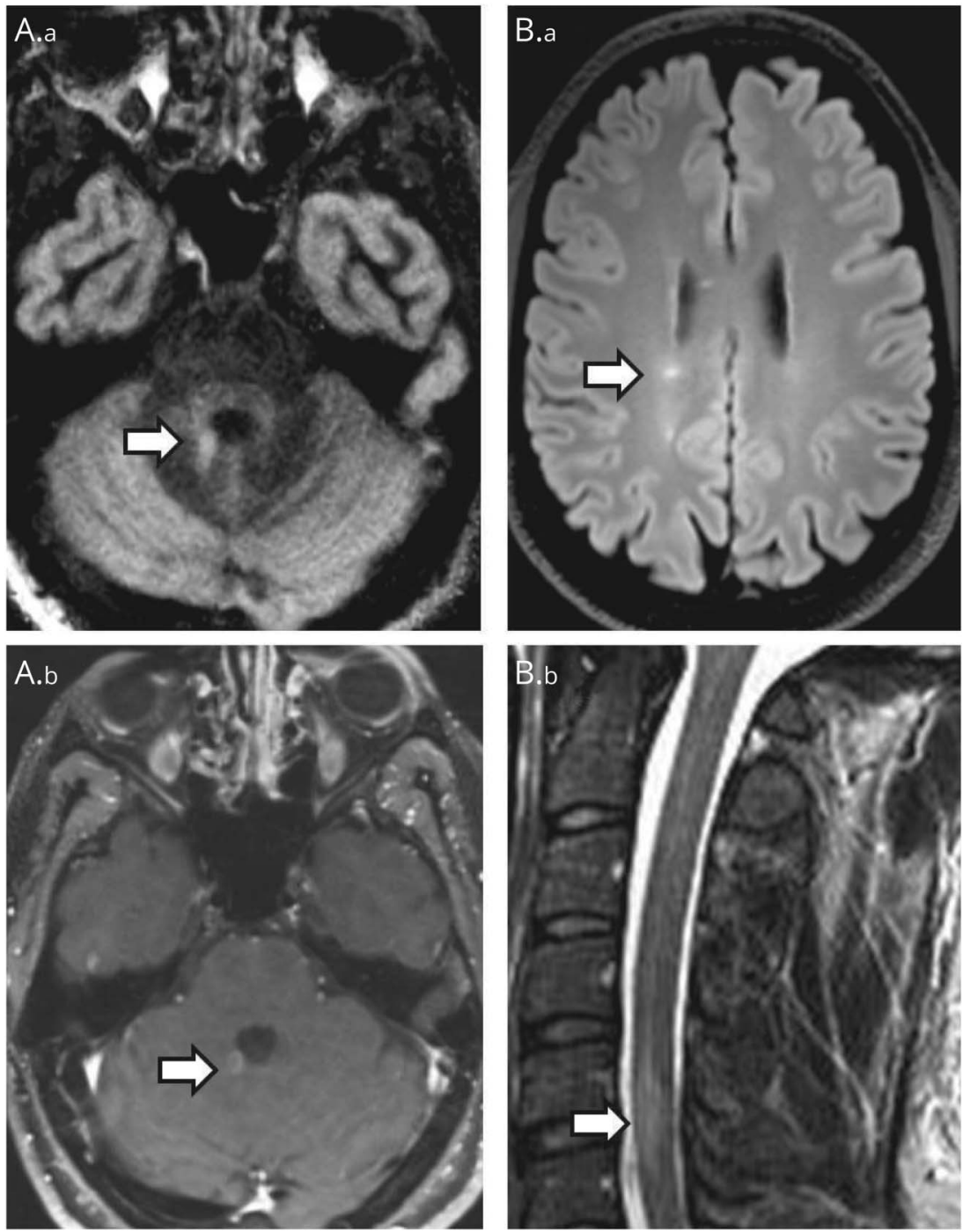

T2-Hyperintense right superior cerebellar peduncle lesion (A.a, arrow) with ring enhancement (A.b, arrow). MRI 2 years later reveals new brain (B.a, arrow) and spinal (B.b, arrow) demyelinating lesions.

A 20-year-old man presented with vertigo followed by hourly episodes of dysarthria and incoordination lasting 5-20 seconds (video 1). Neurologic examination was normal between episodes. The only brain/spine MRI lesion was in the right superior cerebellar peduncle (figure, A). CSF analysis revealed elevated white blood cells $(6 / \mu \mathrm{L}$ [normal, $0-5])$ and oligoclonal

\section{Correspondence}

Dr. Flanagan

flanagan.eoin@mayo.edu 
bands $(\geq 4)$. Paroxysmal dysarthria-ataxia associated with CNS demyelination was diagnosed and episodes resolved with oral acetazolamide $250 \mathrm{mg}$ twice daily. Subsequent MRI of the brain and spine (figure, B) confirmed multiple sclerosis. Paroxysmal dysarthria-ataxia arises from ephaptic transmission within midbrain or cerebellar multiple sclerosis lesions and may respond to carbamazepine or acetazolamide. ${ }^{1}$ It should be distinguished from genetic or contactin-associated protein-like-2 (CASPR2) immunoglobulin G-associated episodic ataxia. ${ }^{2}$

\section{Study Funding}

No targeted funding reported.

\section{Disclosure}

The authors report no disclosures relevant to the manuscript. Go to Neurology.org/N for full disclosures.

\section{Appendix Authors}

\begin{tabular}{lll}
\hline Name & Location & Contribution \\
\hline $\begin{array}{l}\text { Shailee Shah, } \\
\text { MD }\end{array}$ & $\begin{array}{l}\text { Mayo Clinic, } \\
\text { Rochester, MN }\end{array}$ & $\begin{array}{l}\text { Design and conceptualization of } \\
\text { study }\end{array}$ \\
\hline $\begin{array}{l}\text { Bryan T. } \\
\text { Klassen, MD }\end{array}$ & $\begin{array}{l}\text { Mayo Clinic, } \\
\text { Rochester, MN }\end{array}$ & $\begin{array}{l}\text { Design and conceptualization of } \\
\text { study }\end{array}$ \\
$\begin{array}{l}\text { Eoin P. } \\
\begin{array}{l}\text { Flanagan, } \\
\text { MD }\end{array}\end{array}$ & $\begin{array}{l}\text { Mayo Clinic, } \\
\text { Rochester, MN }\end{array}$ & $\begin{array}{l}\text { Design and conceptualization of } \\
\text { study, study supervision }\end{array}$ \\
\hline
\end{tabular}

\section{References}

1. Marcel C, Anheim M, Flamand-Rouviere C, et al. Symptomatic paroxysmal dysarthria-ataxia in demyelinating diseases. J Neurol 2010;257:1369-1372.

2. Joubert B, Gobert F, Thomas L, et al. Autoimmune episodic ataxia in patients with anti-CASPR2 antibody-associated encephalitis. Neurol Neuroimmunol Neuroinflamm 2017;4. 


\section{Neurology}

Teaching Video NeuroImages: Paroxysmal Dysarthria-Ataxia in Multiple Sclerosis

Shailee Shah, Bryan T. Klassen and Eoin P. Flanagan

Neurology 2021;96;e2245-e2246 Published Online before print January 5, 2021

DOI 10.1212/WNL.0000000000011498

This information is current as of January 5,2021

$\begin{array}{ll}\begin{array}{l}\text { Updated Information \& } \\ \text { Services }\end{array} & \begin{array}{l}\text { including high resolution figures, can be found at: } \\ \text { http://n.neurology.org/content/96/17/e2245.full }\end{array} \\ \text { References } & \text { This article cites } 1 \text { articles, } 0 \text { of which you can access for free at: } \\ \text { http://n.neurology.org/content/96/17/e2245.full\#ref-list-1 } & \\ \text { This article, along with others on similar topics, appears in the } \\ \text { following collection(s): } \\ \text { All Demyelinating disease (CNS) } \\ \text { http://n.neurology.org/cgi/collection/all_demyelinating_disease_cns } \\ \text { Gait disorders/ataxia } \\ \text { http://n.neurology.org/cgi/collection/gait_disorders_ataxia } \\ \text { Multiple sclerosis } \\ \text { http://n.neurology.org/cgi/collection/multiple_sclerosis } \\ \text { Information about reproducing this article in parts (figures,tables) or in } \\ \text { its entirety can be found online at: } \\ \text { http://www.neurology.org/about/about_the_journal\#permissions } \\ \text { Information about ordering reprints can be found online: } \\ \text { Pttp://n.neurology.org/subscribers/advertise }\end{array}$

Neurology ${ }^{\circledR}$ is the official journal of the American Academy of Neurology. Published continuously since 1951, it is now a weekly with 48 issues per year. Copyright () 2021 American Academy of Neurology. All rights reserved. Print ISSN: 0028-3878. Online ISSN: 1526-632X.

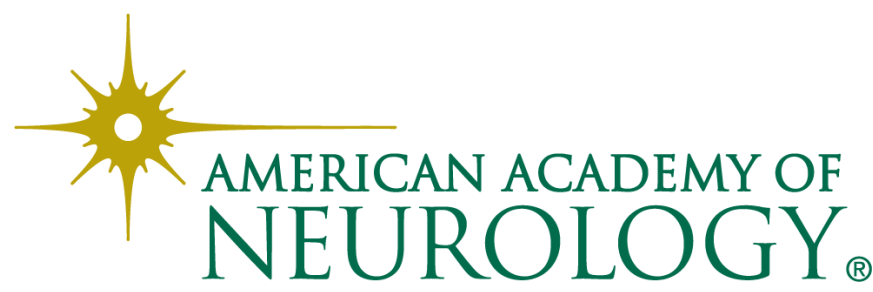

